4 Romão L, Inácio A, Santos S et al: Nonsense mutations in the human $\beta$-globin gene lead to unexpected levels of cytoplasmic mRNA accumulation. Blood 2000; 96: 2895-2901.

5 Zhang J, Maquat LE: Evidence that translation re-initiation abrogates nonsense-mediated mRNA decay in mammalian cells. EMBO J 1997; 16: 826-833.

6 Sanchez-Sanchez F, Ramirez-Castillejo C, Weekes DB et al: Attenuation of disease phenotype through alternative translation initiation in low-penetrance retinoblastoma. Hum Mutat 2006; 28: 159-167.

7 Buisson M, Anczukow O, Zetoune AB et al: The 185delAG mutation (c.68-69delAG) in the BRCA1 gene triggers translation reinitiation at a downstream AUG codon. Hum Mutat 2006; 27: 1024-1029.

8 Paulsen M, Lund C, Akram Z et al: Evidence that translation reinitiation leads to a partially functional Menkes protein containing two copper-binding sites. Am J Hum Genet 2006; 79: 214-229.

9 Puel A, Reichenbach J, Bustamante J et al: The NEMO mutation creating the most-upstream premature stop codon is hypomorphic because of a reinitiation of translation. Am J Hum Genet 2006; 78: 691-701.

10 Zhou W, Song W: Leaky scanning and reinitiation regulate BACE1 gene expression. Mol Cell Biol 2006; 26: 3353-3364.

11 Moumne L, Fellous M, Veitia RA: Deletions in the polyAlaninecontaining transcription factor FOXL2 lead to intranuclear aggregation. Hum Mol Genet 2005; 14: 3557-3564.

12 Chang CC, Gould SJ: Phenotype-genotype relationships in complementation group 3 of the peroxisome-biogenesis disorders. Am J Hum Genet 1998; 63: 1294-1306.

\section{Reply to Inácio et al}

European Journal of Human Genetics (2007) 15, 534. doi:10.1038/sj.ejhg.5201805; published online 7 March 2007

We have recently reviewed the physiological role of nonsense-mediated decay (NMD) and its implications for human genetic disorders. The goal of our review paper was to make the medical community aware that mRNA processing steps must be taken into consideration when attempting to elucidate genotype-phenotype relationships. ${ }^{1}$ Although the exact mechanism for NMD remains to be determined, previous studies in model organisms provide insight into how transcripts containing premature termination codons (PTCs) are recognized by NMD factors and rapidly degraded resulting in loss-of-function alleles. ${ }^{2}$ Evidence from a number of studies suggests a model for the mechanism of NMD surveillance system in which a PTC in the last exon, or within less than $\sim 55$ base pairs from the final intron in penultimate exon (also known as ' $55 \mathrm{nt}$ boundary rule'), is not recognized and may cause expression of large amounts of aberrant truncated proteins with potential harmful effects in cells. We also review and cite the observations that several genes appear to show exception to this rule and thus, mRNAs with nonsense codons present in such positions are subject to the NMD pathway.
This suggests either additional or entirely different cis-acting signals may exist to initiate NMD for select genes. ${ }^{3}$

NMD mechanistic models will require refinement with additional experimental observations as more genes (eg $H B B$ for human $\beta$-globin and BRCA1) are examined. Recent studies have shown that premature nonsense mutations located proximal to an internal AUG in some genes may escape NMD and result in synthesis of N-terminally truncated proteins by a 'translation re-initiation' mechanism. ${ }^{4-6}$ The extent of the effect of escaping NMD by this mechanism and its implications for genotype-phenotype correlations in human disease may also vary depending on both the toxicity of truncated proteins and the nature of traits encoded by different genes. These observations define another factor that can contribute to the complexity and efficiency of the NMD surveillance system in regulating gene expression.

Nevertheless, these findings further support the thesis of our review that one must recognize the role of mRNA and protein processing steps (ie information transfer downstream from the DNA mutation) in conveying the ultimate clinical outcome. It also illustrates the view that understanding of the molecular mechanism of NMD is far from complete and there are no 'universal rules' that have been defined for all genes. Thus, it is essential to carefully verify the potential role of NMD experimentally to enable accurate conclusions regarding genotype-phenotype correlations underlying genetic disorders.

Mehrdad Khajavi ${ }^{1}$ and James R Lupski ${ }^{1,2,3}$

${ }^{1}$ Department of Molecular and Human Genetics, Baylor College of Medicine, Houston, TX, USA;

${ }^{2}$ Department of Pediatrics, Baylor College of Medicine, Houston, TX, USA and

${ }^{3}$ Texas Children's Hospital, Houston, TX, USA E-mail: jlupski@bcm.tmc.edu

\section{References}

1 Khajavi M, Inoue K, Lupski JR: Nonsense-mediated mRNA decay modulates clinical outcome of genetic disease. Eur J Hum Genet 2006; 14: 1074-1081.

2 Lejeune F, Maquat LE: Mechanistic links between nonsense mediated mRNA decay and pre-mRNA splicing in mammalian cells. Curr Opin Cell Biol 2005; 17: 309-315.

3 Wang J, Gudikote JP, Olivas OR, Wilkinson MF: Boundary independent polar nonsense-mediated decay. EMBO R 2002; 3: 274-279.

4 Inácio A, Silva AL, Pinto J et al: Nonsense mutations in close proximity to the initiation codon fail to trigger full nonsensemediated mRNA decay. J Biol Chem 2004; 279: 32170-32180.

5 Buisson M, Anczukow O, Zetoune AB et al: The 185delAG mutation (c.68-69delAG) in the BRCA1 gene triggers translation reinitiation at a downstream AUG codon. Hum Mutat 2006; 27: 1024-1029.

6 Sanchez-Sanchez F, Ramirez-Castillejo C, Weekes DB et al: Attenuation of disease phenotype through alternative translation initiation in low-penetrance retinoblastoma. Hum Mutat 2007; 28: $159-167$. 